\title{
FULLERENES FORMATION IN FLAMES
}

\author{
Jack B. Howard \\ Department of Chemical Engineering \\ Massachusetts Institute of Technology \\ Cambridge, Massachusetts 02139
}

\section{$N 93-\overline{2} 0187$}

\section{Introduction}

Fullerenes are composed of carbon atoms arranged in approximately spherical or ellipsoidal cages resembling the geodesic domes designed by Buckminster Fuller, after whom the molecules were named'. The approximately spherical fullerene, which resembles a soccer ball and contains sixty carbon atoms $\left(C_{60}\right)$, is called buckminsterfullerene. The fullerene containing seventy carbon atoms $\left(\mathrm{C}_{70}\right)$ is approximately ellipsoidal, similar to a rugby ball. Fullerenes were first detected in 1985, in carbon vapor produced by laser evaporation of graphite. The closed shell structure, which has no edge atoms vulnerable to reaction, was proposed to explain the observed high stability of certain carbon clusters relative to that of others at high temperatures and in the presence of an oxidizing gas.

The proposed structure remained unconfirmed until 1990, when samples large enough for spectroscopy were produced by vaporization of graphite rods with resistive heating under inert atmosphere ${ }^{2}$. This method was quickly adopted in several research groups $^{3-5}$ and in small new companies. Fullerene samples soon became available, and the pace of research accelerated to an intense level. The interest rapidly expanded to include a still growing list of molecular and crystalline properties of fullerenes, as well as fullerenes with metals and other elements inside the cages, and fullerenes with hydrogen, oxygen, methyl, methylene, phenyl, or other functional groups or cross-links.

The suggested potential applications for fullerenes include superconductors, lubricants, catalysts, high energy fuels, polymers and biomaterials. The chemistry of fullerenes formation is being studied to provide a basis for the design and operation of fullerene synthesis reactors, and for the identification of new fullerene types and derivatives.

The possibility that fullerenes may be formed in sooting flames was suggested ${ }^{6-9}$ early in fullerenes research. Zang et al. ${ }^{6}$ considered the possible role of carbon shell structures in the formation and morphology of soot. Kroto and McKay ${ }^{7}$ described a carbon nucleation scheme involving quasi-icosahedral spiral shell carbon 
particles, and suggested it may apply to soot. Curl and Smalley ${ }^{8}$ suggested that carbon nets in the form of spiral structures may be important to soot formation in flames. Recent reviews of these concepts are given by Kroto et al. ${ }^{10-12}$

All-carbon ions having charge/mass rat os similar to those reported for fullerenes in graphite vaporization were observed by Homann et al. ${ }^{13-15}$ using on-line molecular beam/mass spectrometric probing of low-pressure premixed benzene-oxygen and acetylene-oxygen flames. Iijima ${ }^{16}$ published an electron micrograph of a soot particle in which a circular feature was interpreted to be evidence of a fullerene. Malhotra and Ross ${ }^{17}$ using field ionization mass spectrometry studied several soots from pyrolysis and combustion processes but found no peaks corresponding to fullerenes.

The presence of $C_{60}$ and $C_{70}$ fullerenes in substantial quantities was reported from spectroscopic analysis of samples collected from low-pressure premixed benzene-oxygen flames at $\mathrm{MIT}^{18,19}$. The presence and group behavior of high molecular weight compounds having molecular-weights up to about $1000 \mathrm{~g} / \mathrm{mole}$ in benzene-oxygen flames had been studied earlier at MIT using molecular-beam sampling with on-line mass spectrometry $y^{2021}$ as well as probe collection of condensible material including soot with subsequent analysis by solvent extraction and other methods ${ }^{22}$. Intriguing but inconclusive evidence of the presence of fullerenes had been seen from both on-line mass spectra $a^{21,23}$ and exploratory fast atom bombardment mass spectra of collected samples ${ }^{23}$. The presence of fullerenes in these flames was finally established ${ }^{18,19}$, soon after the discovery ${ }^{2}$ and early implementation ${ }^{3-5}$ of the graphite vaporization process for producing macroscopic quantities of fullerenes. The same solvent extraction and spectroscopic techniques employed in the graphite vaporization studies were applied successfully in the study of the flame samples.

The knowledge of fullerenes formation in flames has grown significantly during the short time since this process was first established. The effects of combustion conditions on the distribution and yields of $C_{60}$ and $C_{70}$ fullerenes have been studied and the amount of fullerenes formed at different distances or times through the reaction zone of selected flames has been measured. Flame synthesis is found to offer not only an alternative method for large scale fullerenes production, but an ability to control the distribution of products (e.g., the $C_{70} / C_{60}$ ratio) over a larger range than previously realized. Also, a range of fullerenes including metastable isomers can be produced in flames ${ }^{24}$. Plausible mechanisms of fullerenes formation in flames have been proposed and subjected to preliminary kinetics testing against data ${ }^{25}$. These advances are summarized below.

\section{Current Knowledge}

Fullerenes can be synthesized in substantial quantities in flames. Most of the research on fullerenes formation in flames has been performed with subatmospheric pressure, laminar, premixed flames of benzene and oxygen, with or without an inert 
diluent gas, but acetylene has also been used successfully. The following conclusions about yields and products refer to the use of benzene fuel.

The largest yields of fullerenes are produced in sooting flames, but not under the most heavily sooting conditions. The largest conversion of carbon to soot is about $12 \%$ in fullerene forming flames, but the largest yields and production rates of fullerenes are observed when about $2-3 \%$ of the carbon is converted to soot. Small yields of fullerenes are formed in nonsooting flames near the critical conditions for impending soot formation.

The largest yield of $\mathrm{C}_{60}+\mathrm{C}_{70}$ as a percentage of soot is $20 \%$, observed at a pressure of 37.5 torr, a C/O atomic ratio of 0.959 and $25 \%$ helium. The largest $C_{60}+C_{70}$ yield on a basis of percentage of carbon fed is about $0.5 \%$, and the largest $\mathrm{C}_{60}+\mathrm{C}_{70}$ production rate $(\mathrm{g} / \mathrm{hr})$ was observed at a pressure of 69 torr, a C/O ratio of 0.989 and $25 \%$ helium.

The $\mathrm{C}_{70} / \mathrm{C}_{60}$ molar ratios observed under different flame conditions are in the range $0.26-8.8$, compared to $0.02-0.18$ for the graphite vaporization method. The ratio is typically 1.5 to 1.8 for the flame conditions of largest $\mathrm{C}_{60}+\mathrm{C}_{70}$ production rates and yields. The largest values of this ratio are observed under conditions where the fullerene yields and production rates are relatively low.

The ability to promote the yield of certain products by adjustment of flame conditions apparently extends to larger fullerenes, based on exploratory work with solvents suitable for large fullerenes.

Isomers of fullerene $C_{60}$ are produced in varying amounts in flames under different conditions. Although the isomers' structures are not yet known in detail, they necessarily must include abutting five-membered rings, which have previously been assumed to be avoided because of their high strain energy. Many of the isomers are thermally metastable, the $\mathrm{C}_{60}$ isomers having a half-life of $1 \mathrm{hr}$ in toluene at $111^{\circ} \mathrm{C}$.

Flame derived fullerenes also include isomers of $\mathrm{C}_{70}, \mathrm{C}_{60} \mathrm{O}, \mathrm{C}_{70} \mathrm{O}, \mathrm{C}_{76}, \mathrm{C}_{84}, \mathrm{C}_{90}$ and $\mathrm{C}_{94}$, and many hydrogen-containing complexes such as $\mathrm{C}_{60} \mathrm{H}_{2}, \mathrm{C}_{60} \mathrm{H}_{4}, \mathrm{C}_{70} \mathrm{H}_{2},\left[\mathrm{C}_{60}\left(\mathrm{CH}_{2}\right)\left(\mathrm{H}_{2}\right)\right]$ or $\left[\mathrm{C}_{60}(\mathrm{H})\left(\mathrm{CH}_{3}\right)\right]$, and others.

Fullerenes in flames are formed in the presence of hydrogen and oxygen as well as carbon. The formation of fullerenes is the net result of formation and destruction reactions, and the fullerenes concentration profile exhibits a peak at lower $\mathrm{C} / \mathrm{O}$ ratios but become monotonically increasing with distance from the burner as the $\mathrm{C} / \mathrm{O}$ ratio is increased. The formation of fullerenes in sooting flames occurs several milliseconds later than soot formation.

Fullerenes formation in flames is a molecular weight growth process analogous to the formation of PAH and soot but involving curved and hence strained structures. 
A detailed mechanism of the formation of $C_{60}$ and $C_{70}$ fullerenes in flames has been constructed based on the types of reactions already used in describing $\mathrm{PA} \hat{\mathrm{H}}$ and soot growth, but including intramolecular rearrangements and other reactions needed to describe the evolution of the unique structural features of the fullerenes.

\section{Potential for Microgravity Research}

Potential topics for microgravity research include fullerenes formation in both diffusion premixed and laminar premixed flames. In the case of diffusion flames, experiments under microgravity conditions would complement measurements at $1 \mathrm{~g}$ in determining the effect of laminar flame structure on the extent of production of the well known $C_{60}$ and $C_{70}$ fullerenes, and on the formation of novel fullerenes. In addition, the measurements would permit preliminary projections of the prospects for fullerenes synthesis in turbulent diffusion flames. Measurements in premixed flames under microgravity conditions would allow the extent of $C_{60}$ and $C_{70}$ formation and the formation of novel fullerenes to be studied under conditions where the behavior is already well known except for the effect of gravity.

\section{Acknowledgements}

The author is grateful to M.K. Chung, A.G. Dietz III, L.M. Giovane, D.G. Goldenson, M.E. Johnson, R.J. Juba, Jr., A.L. Lafleur, Y. Makarovsky, S. Mitra, M.D. Nyström, C.J. Pope, L.W. Theiss, and T.K. Yadav for valuable collaboration and/or laboratory work; to the Division of Chemical Sciences, Office of Basic Energy Sciences, Office of Energy Research, U.S. Department of Energy, for financial support under grant No. DE-FG02-84ER13282; and to the National Institute of Environmental Health Sciences for analytical support under Center Grant EHS-5P30-ES02109-10 and Program Grant EHS-5P01-ES01640-11.

\section{References}

1. Kroto, H.W., Heath, J.R., O'Brien, S.C., Curl, R.F., and Smalley, R.E.: Nature 318, 162 (1985).

2. Krätschmer, W., Lamb, L.D., Fostiropoulos, K., and Huffman, D.R.: Nature 347, 354 (1990).

3. Taylor, R., Hare, J.P., Abdul-Sada, A.K., and Kroto, H.W.: J. Chem. Soc., Chem. Commun., 1423-1425 (1990).

4. Ajie, H., Alvarez, M.M., Anz, S.J., Beck, R.D., Diederich, F., Fostiropoulos, K., Huffman, D.R., Krätschmer, W., Rubin, Y., Schriver, K.E., Sensharma, D., and Whetten, R.L.: J. Phys. Chem. 94, 8630 (1990). 
5. Haufler, R.E., Conceicao, J., Chibante, L.P.F., Chai, Y., Byrne, N.E., Flanagan, S., Haley, M.M., O'Brien, S.C., Pan, C., Xiao, Z., Billups, W.E., Ciufolini, M.A., Hauge, R.H., Margrave, J.L., Wilson, L.J., Curl, R.F., and Smalley, R.E.: J. Phys. Chem. 94, 8634 (1990).

6. Zhang, Q.L., O'Brien, S.C., Heath, J.R., Liu, Y., Curl, R.F., Kroto, H.W., and Smalley, R.E.: J. Phys. Chem. 90, 525 (1986).

7. Kroto, H.W. and McKay, K.: Nature 331, 328 (1988).

8. Curl R.F. and Smalley, R. E.: Science 242, 1017 (1988).

9. Kroto, H.W.: Science 242, 1139 (1988).

10. Kroto, H.W., Allaf, A.W., and Balm, S.P.: Chem. Rev. 91, 1213 (1991).

11. Kroto, H.W.: J. Chem. Soc. Faraday Trans. 87 (18), 2871 (1991).

12. Kroto, H.W.: Angew. Chem. Int. Ed. Engl. 31, 111 (1992).

13. Gerhardt, Ph., Löffler, S., and Homann, K.H.: Chem. Phys. Lett. 137, 306 (1987).

14. Gerhardt, Ph, Löffler, S., and Homann, K.H.: Twenty-Second Symposium (International) on Combustion, p. 395, The Combustion Institute, 1989.

15. Löffler, S. and Homann, K.H.: Twenty-Third Symposium (International) on Combustion, p. 355, The Combustion Institute, Pittsburgh, 1991.

16. Iijima, S.: J. Phys. Chem. 91, 3466 (1987).

17. Malhotra, R. and Ross, D.S.: J. Phys. Chem. 95, 4599 (1991).

18. Howard, J. B., McKinnon, J.T., Makarovsky, Y., Lafleur, A.L., and Johnson, M.E.: Nature 352, 139 (199.).

19. McKinnon, J.T., Bell, M.W., and Barkley, R.M.: Combustion and Flame 88, 102 (1992).

20. Bittner, J.D. and Howard, J.B.: Eighteenth Symposium (International) on Combustion, p. 110, The Combustion Institute, 1981.

21. Howard, J.B. and Bittner, J.D.: Soot in Combustion Systems and Its Toxic Properties (J. Lahaye and G. Prado, Eds.), pp. 57-91, Plenum, 1983. 
22. McKinnon, J.T.: Ph.D. Thesis, MIT (1989).

23. Pope, C.J.: M.S. Thesis, MIT (1988).

24. Anacleto, J.F., Perreault, H., Boyd, R.K., Pleasance, S., Quilliam, M.A., Sim, P.G., Howard, J. B., Makarovsky, Y., and Lafleur, A.L.: Rapid Communications in Mass Spectroscopy 6, 214 (1992).

25. Pope, C.J.: Thesis, MT (in preparation). 


\section{COMMENTS}

Question (G.M. Faeth, University of Michigan: You mostly discussed Fullerenes formation in premixed flames. Have there been corresponding studies in nonpremixed flames?

Answer: I know of no published studies of Fullerenes formation in diffusion llames. Such studics would be of much interest, given the contrasts between the diffusion and premixed flame structures. 
